\title{
Risk factors for wound infection after off-pump coronary artery bypass grafting: Should bilateral internal thoracic arteries be harvested in patients with diabetes?
}

Jota Nakano, MD, ${ }^{a}$ Hitoshi Okabayashi, MD, PhD, ${ }^{b}$ Michiya Hanyu, MD, PhD, ${ }^{\text {a }}$ Yoshiharu Soga, MD, PhD, ${ }^{a}$

Takuya Nomoto, MD, PhD, ${ }^{a}$ Yoshio Arai, MD, PhD, ${ }^{a}$ Takehiko Matsuo, MD, ${ }^{a}$ Masashi Kai, MD, ${ }^{a}$ and

Masahide Kawatou, $\mathrm{MD}^{\mathrm{a}}$

From the Department of Cardiovascular Surgery, Kokura Memorial Hospital, Kitakyusyu City, Fukuoka, Japan ${ }^{\text {a }}$, and the Department of Cardiovascular Surgery, Iwate Medical University, Memorial Heart Center, Iwate, Japan. ${ }^{\text {b }}$

Received for publication April 26, 2007; revisions received Aug 3, 2007; accepted for publication Nov 5, 2007.

Address for reprints: Jota Nakano, MD, Cardiovascular Surgery, Kokura Memorial Hospital, Kifune 1-1, Kokurakitaku, Kitakyusyu City, Fukuoka, Japan (E-mail: jnakano@ ca2.so-net.ne.jp).

J Thorac Cardiovasc Surg 2008;135:540-5 0022-5223/\$34.00

Copyright (C) 2008 by The American Association for Thoracic Surgery

doi:10.1016/j.jtcvs.2007.11.008
Objective: Wound infection is a rare but life-threatening complication after coronary artery bypass grafting. Risk factors for wound infection after off-pump bypass grafting and the validity of using bilateral internal thoracic arteries harvested in a skeletonized fashion remain unclear, especially in patients with diabetes.

Methods: The data of 1500 consecutive patients having off-pump bypass grafting were prospectively collected from our database based on EuroSCORE. This cohort represents $95 \%$ of all patients undergoing coronary bypass during that period and $77 \%$ of patients undergoing off-pump bypass grafting who received bilateral internal thoracic artery grafts. Univariate and multivariate analyses were performed for patients with and without wound infection and in the diabetic subgroup.

Results: Ninety-eight patients had wound infections: 76, impaired wound healing; 7, superficial sternal wound infection; and 12, deep sternal wound infection. Patients with wound infections had a higher prevalence of female gender, atrial fibrillation, history of congestive heart failure, chronic renal failure, peripheral vascular disease, and diabetes. Patients with a wound infection more frequently had bilateral internal thoracic artery grafting, longer operation time, longer hospital stay, and a higher mortality rate. Blood transfusions were required in $43.9 \%$ of patients with wound infections and $28.1 \%$ of those without wound infections. On logistic regression analysis, female gender and history of congestive heart failure, chronic renal failure, and diabetes mellitus were independent risk factors for wound infection. In patients with diabetes, female gender, atherosclerosis obliterans, chronic renal failure, and use of bilateral internal thoracic artery grafts were independent risk factors for wound infection.

Conclusions: Risk factors for wound infection after off-pump coronary artery bypass grafting are comparable with those previously reported for conventional bypass grafting. In patients with diabetes, the use of bilateral internal thoracic arteries, even when harvested in a skeletonized fashion, is a risk factor. Thus, appropriate precautions should be taken in patients with diabetes.

$\mathrm{W}$ ound infection is a serious complication after coronary artery bypass grafting $(\mathrm{CABG})$. In the past decade, investigators found that, compared with conventional on-pump CABG, off-pump CABG (OPCAB) appeared to reduce the rate of morbidity and mortality. ${ }^{1}$ Sabik and associates ${ }^{2}$ demonstrated that the OPCAB procedure reduced morbidity, including wound infection. Some studies dealing with the beating heart technique mentioned wound infections, ${ }^{2-4}$ but few of them dealt with the risk factors for wound infection in patients undergoing OPCAB. ${ }^{5}$

The correlation between post-CABG wound infections and the use of the internal thoracic artery (ITA) is also widely known. In particular, in patients with diabetes mellitus, single ITA (SITA), and bilateral ITA (BITA), harvesting increases the rate of sternal wound infection. ${ }^{67}$ An increasing number of reports show the benefits of 


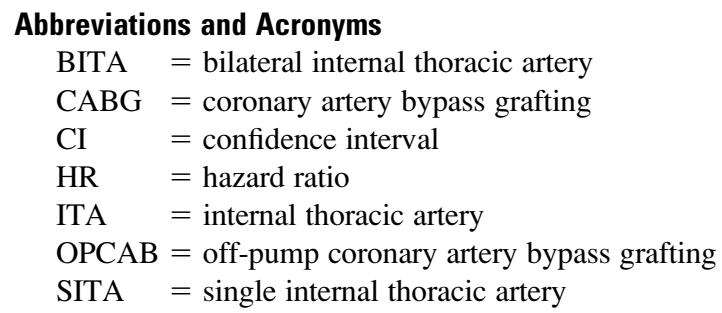

BITA over SITA with respect to long-term survival and freedom from reintervention. ${ }^{8}$ However, many surgeons have hesitated to adopt BITA grafting to avoid wound infection; according to The Society of Thoracic Surgeons database, less than $4 \%$ of patients undergoing CABG received BITA grafting from 2002 to $2004 .^{9}$

A reduction of wound infections was noted in some reports when BITA grafts were harvested in a skeletonized fashion. ${ }^{4,10-13}$ Among those reports, there are some indicating that, even in patients with diabetes, BITA harvesting does not increase the wound infection rate. ${ }^{10,12,13}$ Computed tomographic scans done after harvesting ITA grafts in a pedicled fashion showed a reduction in the vascularity of the sternum. ${ }^{14}$ This decrease in vascularity might impair sternal wound healing, and this would lead to an increased infection rate. On the other hand, Boodhwani and associates ${ }^{15}$ did a prospective, within-patient, randomized trial and found that, after surgery, sternal blood flow was greater on the skeletonized side than on the pedicled side. We hypothesized that skeletonized BITAs could be harvested even in high-risk patients, including those with diabetes. Thus, this study assessed wound infection after CABG done in combination with the off-pump beating heart technique and ITA harvesting in a skeletonized fashion.

\section{Patients and Methods \\ Study Design}

The data of all patients who had OPCAB in our institution between 2000 and 2005 were reviewed. One of the aims of this study was to identify the risk factors for wound infection. The other aim was to identify the relationship between BITA harvesting and wound infection, especially in patients with diabetes.

\section{Patients}

Between 2000 and 2005, 1500 patients had isolated OPCAB done by a single surgeon (H.O.). During the same period, 76 patients who had CABG with cardiopulmonary bypass and 494 patients who had a concomitant procedure other than CABG (eg, valve repair and/or replacement, replacement of thoracic aorta) were excluded from this study. Almost half of the 76 patients having conventional $\mathrm{CABG}$ were in hemodynamically unstable condition, even with an intra-aortic balloon pump; the remaining patients had previous cardiac surgery and required cardiopulmonary bypass for resternotomy and exposure. The perioperative data of all patients were collected prospectively.

\section{Data Collection}

The perioperative data were collected based on the definitions of the European System for Cardiac Operative Risk Evaluation (EuroSCORE). ${ }^{16}$

1. Preoperative characteristics that were collected included age, gender, New York Heart Association and Canadian Cardiovascular Society classes, history of percutaneous transluminal coronary angioplasty, previous cardiac operations, unstable angina, congestive heart failure, recent myocardial infarction, presence of old myocardial infarction lesions, left main stem stenosis greater than $50 \%$, the number of diseased vessels, ejection fraction obtained by left ventriculogram and/or echogram, degree of mitral regurgitation, history of atrial fibrillation, previous cerebrovascular accident (including infarctions and transient ischemic attacks), chronic renal failure (serum creatinine greater than 200 $\mathrm{mmol} / \mathrm{L}$ ), end-stage renal failure requiring dialysis, chronic obstructive pulmonary disease, peripheral vascular disease including atherosclerosis obliterans, abdominal aortic aneurysm, cerebrovascular disease, and preoperative critical status. In addition to the EuroSCORE data, the following data were also collected: hypertension, hyperlipidemia, and diabetes and its treatment (diet, oral hypoglycemic agent, insulin, or none). The hypertension, hyperlipidemia, and diabetes mellitus categories included all patients who had been diagnosed before admission. In patients with a diagnosis of diabetes mellitus, free blood glucose and hemoglobin $A_{1 c}$ were routinely measured before surgery.

2. Intraoperative factors included EuroSCORE operation status (elective or emergency), use of an intra-aortic balloon pump, number of distal anastomoses, graft selection and the anastomosed regions, and operation time.

3. Postoperative variables included transfusions, cardiac rhythm at discharge, maximum creatine kinase MB, New York Heart Association/Canadian Cardiovascular Society class at discharge, postoperative coronary angiography and/or multidetector computed tomography results, major morbidity, and cause of in-hospital death. Blood transfusions were included only when administered before wound infection debridement. Major morbidity included respiratory failure (mechanical ventilation over 48 hours), renal dysfunction necessitating dialysis, low output syndrome, resternotomy for bleeding, gastrointestinal bleeding, cerebrovascular accident, and wound infection.

4. Wound infections were categorized into three types: impaired wound healing, superficial wound infections, and deep wound infections. Impaired wound healing was defined as wound erythema and a purulent discharge necessitating additional antibiotic agents and/or hospitalization. Diagnoses of superficial and deep infections were based on the wound swab culture results. All wound infections were defined on the basis of the guidelines of the US Center for Disease Control and included patients who received debridement and required wound resuturing. ${ }^{17}$ The time interval for assessment of wound infection was the in-hospital period. 


\section{OPCAB Procedures}

Graft selection was based on the following strategies: (1) Patients with severely stenosed $(>75 \%)$ multivessel disease involving the left coronary arteries received BITA grafts; (2) for mildly stenosed lesions, saphenous vein grafts were used as additional conduits; (3) the right gastroepiploic artery was used for significantly stenosed $(>75 \%)$ right coronary arteries. ITAs (both SITA and BITA) and gastroepiploic artery were harvested in a skeletonized fashion with an ultrasonic scalpel (Harmonic Scalpel; Ethicon EndoSurgery, CVG, Cincinnati, Ohio) by trained surgeons. The left ITA was usually anastomosed to the left anterior descending region, and the right ITA was usually anastomosed to the left circumflex system via the transverse sinus. To achieve complete revascularization, we harvested saphenous vein grafts, right gastroepiploic arteries, or radial arteries as additional conduits.

\section{Perioperative Management (Avoidance of Wound Infection)}

On the day before surgery, hair around the surgical site was removed with clippers, and all patients were washed with a povidone-iodine soap solution. In the operating theater, a surgical scrub was performed on the body wall and legs with a povidone-iodine solution. An antimicrobacterial drape (Ioban; 3M, Brookings, SD) was applied to the surgical site. Before skin incision, cefazolin (1 g) was given initially; additional cefazolin was given every 4 hours during OPCAB surgery. After completion of the anastomoses, the surgical site was washed with $1 \mathrm{~L}$ of warm saline, and another $1 \mathrm{~g}$ of cefazolin was sprayed around the surgical site before skin closure.

The presternal space was closed with two layers of nonabsorbable monofilament single sutures, followed by a continuous absorbable skin suture. Prophylactic intravenous antibiotics were administered until postoperative day 2.

During the procedure, blood glucose was measured routinely 4 or 5 times. An intravenous insulin infusion was given when blood glucose exceeded $150 \mathrm{mg} / \mathrm{dL}$.

\section{Statistical Analysis}

Statistical analyses were performed with Stat-View version 5.0 (SAS Institute, Inc, Cary, NC). Univariate analyses were performed with the $\chi^{2}$ test or Fisher exact test for categorical variables and with the Student $t$ test or the Mann-Whitney $U$ test for numerical variables. Multivariate analyses were performed by additive stepwise logistic regression. Results are expressed as mean \pm SD.

\section{Results}

Wound infection occurred in $98(6.5 \%)$ of the 1500 OPCAB patients: 79 had impaired wound healing, $7(0.47 \%)$ had a superficial infection, and $12(0.8 \%)$ had a deep infection (sternal osteomyelitis and/or mediastinitis). Table 1 shows the baseline characteristics of patients with and without wound infection. Among patients with a wound infection, there was a greater proportion of women and a higher prevalence of atrial fibrillation, history of congestive heart failure, chronic renal failure (including end-stage renal failure on dialysis), peripheral vascular disease (atherosclerosis obliterans, abdominal aortic aneurysm, and cerebrovascular disease), and diabetes (both insulin-dependent and non-insulin-dependent).
TABLE 1. Preoperative characteristics of patients with/ without wound infection

\begin{tabular}{|c|c|c|c|}
\hline Variables & $\begin{array}{l}\text { Patients with } \\
\text { no infection } \\
\text { (n=1402) }\end{array}$ & $\begin{array}{l}\text { Patients with } \\
\text { infection } \\
(\mathbf{n}=98)\end{array}$ & $P$ value \\
\hline Age & $67.7 \pm 9.4$ & $69.3 \pm 8.1$ & .1065 \\
\hline Female gender & $367(26.2 \%)$ & $43(43.9 \%)$ & .0001 \\
\hline NYHA class $\geq 3$ & $12(0.86 \%)$ & $1(1.0 \%)$ & .8685 \\
\hline Atrial fibrillation & $28(2.0 \%)$ & $5(5.1 \%)$ & .0428 \\
\hline Prior cardiac operation & $31(2.2 \%)$ & 0 & .1369 \\
\hline CHF & $170(12.1 \%)$ & $25(25.5 \%)$ & .0001 \\
\hline \multicolumn{4}{|l|}{ LV dysfunction } \\
\hline $\begin{array}{l}\text { Moderate } \\
\quad \text { (EF 30\%-50\%) }\end{array}$ & $290(20.7 \%)$ & $26(26.5 \%)$ & NA \\
\hline Poor $(\mathrm{EF}<30 \%)$ & $33(2.4 \%)$ & $3(3.1 \%)$ & .6582 \\
\hline CRF & $91(6.5 \%)$ & $18(18.4 \%)$ & $<.0001$ \\
\hline ESRF on dialysis & $66(4.7 \%)$ & $13(13.3 \%)$ & .0002 \\
\hline COPD & $39(2.8 \%)$ & $3(3.1 \%)$ & .8712 \\
\hline PVD & $275(19.6 \%)$ & $29(29.6 \%)$ & .0175 \\
\hline Diabetes mellitus & $631(45.0 \%)$ & $62(63.3 \%)$ & .0005 \\
\hline $\begin{array}{l}\text { Taking hypoglycemic } \\
\text { agents }\end{array}$ & $476(34.0 \%)$ & $39(40.0 \%)$ & NA \\
\hline Taking insulin & $155(11.1 \%)$ & $23(23.5 \%)$ & .0002 \\
\hline Additive EuroSCORE & $4.6 \pm 3.0$ & $5.5 \pm 3.1$ & .0020 \\
\hline Logistic EuroSCORE & $5.4 \pm 9.2$ & $7.4 \pm 10.7$ & .0119 \\
\hline
\end{tabular}

$N Y H A$, New York Heart Association; $C H F$, congestive heart failure; $L V$, left ventricle; $E F$, ejection fraction; $C R F$, chronic renal failure; $E S R F$, end-stage renal failure; $C O P D$, chronic obstructive pulmonary disease; $P V D$, peripheral vascular disease; $N A$, not applicable.

The two groups had similar left ventricular function. There was no significant difference between patients with and without infection with respect to mean age, prior cardiac operations, or chronic obstructive pulmonary disease. Both the additive and the logistic EuroSCOREs were higher in the wound infection group (additive $4.6 \pm 3.0,5.5 \pm 3.1$, $P=.0020$; logistic $5.4 \pm 9.2,7.4 \pm 10.7, P=.01$ ).

Perioperative variables are shown in Table 2. Compared with those without wound infection, patients with wound infection more frequently received BITA grafts and had a longer operation time. Blood transfusions were required in $43.9 \%$ of patients with a wound infection (during and after OPCAB surgery), whereas $28.1 \%$ of those without a wound infection required a transfusion $(P=.0009)$. Both the hospital stay and mortality rate were higher in the wound infection group. Overall, $9(0.6 \%)$ patients required a resternotomy for bleeding, $38(2.5 \%)$ had respiratory failure necessitating mechanical ventilation for longer than 48 hours, 30 (2.0\%) required hemodialysis owing to postoperative renal function deterioration, $21(1.4 \%)$ had a stroke confirmed by computed tomography and/or magnetic resonance imaging, and 11 $(0.7 \%)$ had low output syndrome.

Logistic regression was done to identify independent risk factors for wound infection after OPCAB surgery. Table 3 shows that female gender (hazard ratio; HR, 2.2; 95\% 
TABLE 2. Perioperative characteristics of patients with/ without wound infection

\begin{tabular}{lccc}
\hline \multicolumn{1}{c}{ Variables } & $\begin{array}{c}\text { Patients with } \\
\text { no infection } \\
\text { (n = 1402) }\end{array}$ & $\begin{array}{c}\text { Patients with } \\
\text { infection } \\
\text { (n = 98) }\end{array}$ & $\begin{array}{c}\boldsymbol{P} \\
\text { value }\end{array}$ \\
\hline Emergency & $113(8.1 \%)$ & $6(6.1 \%)$ & .4926 \\
Conduits & $1373(97.9 \%)$ & $98(100 \%)$ & .1505 \\
SITA (LITA or RITA) & $1081(77.1 \%)$ & $84(85.7 \%)$ & .0479 \\
BITA & $382(27.2 \%)$ & $34(34.7 \%)$ & .1114 \\
BITA + GEA & $288 \pm 71$ & $304 \pm 81$ & .0310 \\
Operation time (min) & $394(28.1 \%)$ & $43(43.9 \%)$ & .0009 \\
Transfusion & $17.0 \pm 14.0$ & $44.2 \pm 50.8$ & $<.0001$ \\
Hospital stay (days) & $6(0.40 \%)$ & $6(6.1 \%)$ & $<.0001$ \\
Mortality & & &
\end{tabular}

SITA, Single internal thoracic artery; LITA, left internal thoracic artery; RITA, right internal thoracic artery; BITA, bilateral internal thoracic arteries; GEA, gastroepiploic artery.

confidence interval [CI], 1.4-3.4), history of congestive heart failure (HR, 1.9; 95\% CI, 1.2-3.2), chronic renal failure (HR, $3.0 ; 95 \% \mathrm{CI}, 1.7-5.3$ ), and diabetes mellitus (HR, 1.8; 95\% CI, 1.2-2.8) were independent risk factors for wound infection.

Univariate and multivariate analyses were also done for the subgroup of patients with diabetes. As shown in Table 4 , female gender, history of congestive heart failure, chronic renal failure (including end-stage renal failure on hemodialysis), insulin-dependent diabetes, atherosclerosis obliterans, use of BITA grafts, and blood transfusion were risk factors for wound infection in diabetic patients; all had a $P$ value less than .05 on univariate analyses. On multivariate analysis with logistic regression, female gender (HR, 3.5; 95\% CI, 2.0-6.0), atherosclerosis obliterans (HR, 2.8; 95\% CI, 1.45.4), chronic renal failure (HR, 2.3; 95\% CI, 1.1-4.8), and use of BITA grafts (HR, 2.5; 95\% CI, 1.1-6.1) were found to be independent risk factors for wound infection in the diabetic subgroup (Table 5).

\section{Discussion}

Wound infection is a rare but life-threatening complication in patients undergoing cardiac surgery. CABG is an independent risk factor for deep sternal infection after sternotomy. Sabik and associates ${ }^{2}$ reported that OPCAB reduced morbid-

TABLE 3. Multivariate analysis of risk factors for wound infection

\begin{tabular}{lrccc}
\hline \multicolumn{1}{c}{ Variables } & Wald $\boldsymbol{\chi}^{\mathbf{2}}$ & $\boldsymbol{P}$ value & HR & $\mathbf{9 5 \%} \mathbf{~ C I}$ \\
\hline Female gender & 13.083 & .0003 & 2.2 & $14-3.4$ \\
CHF & 6.773 & .0093 & 1.9 & $1.2-3.2$ \\
CRF & 13.558 & .0002 & 3.0 & $1.7-5.3$ \\
DM & 7.256 & .0071 & 1.8 & $1.2-2.8$ \\
\hline
\end{tabular}

$H R$, Hazard ratio; $\mathrm{Cl}$, Confidence interval; $\mathrm{CHF}$, congestive heart failure; $C R F$, chronic renal failure; $D M$, diabetes mellitus. Overall $\chi^{2}=306.228$ with $4 d f$, $P<.0001$
TABLE 4. Univariate analyses of risk factors for wound infection in diabetic patients

\begin{tabular}{lccr}
\hline \multicolumn{1}{c}{ Variables } & $\begin{array}{c}\text { Patients with } \\
\text { no infection } \\
\text { (n= 631) }\end{array}$ & $\begin{array}{c}\text { Patients with } \\
\text { infection } \\
\text { (n= 62) }\end{array}$ & $\begin{array}{c}\boldsymbol{P} \\
\text { value }\end{array}$ \\
\hline Female gender & $27.1 \%$ & $53.2 \%$ & $<.0001$ \\
CHF & $15.5 \%$ & $29.0 \%$ & .0066 \\
CRF (Cre > 200 mmol) & $8.1 \%$ & $19.4 \%$ & .0032 \\
ESRF on HD & $5.7 \%$ & $14.5 \%$ & .0072 \\
Diabetes taking insulin & $24.6 \%$ & $37.1 \%$ & .0311 \\
ASO & $10.6 \%$ & $25.8 \%$ & .0004 \\
BITA & $78.3 \%$ & $90.3 \%$ & .0255 \\
Transfusion & $31.2 \%$ & $45.2 \%$ & .0253 \\
\hline
\end{tabular}

$C H F$, Congestive heart failure; $C R F$, chronic renal failure; $C r e$, creatinine; $E S R F$, end-stage renal failure; $H D$, hemodialysis; $A S O$, atherosclerosis obliterans; $B I T A$, bilateral internal thoracic arteries.

ity, including sternal wound infection, compared with the on-pump procedure. Thus, since 2000 , we have adopted the "off-pump" technique and routinely use BITA for significantly stenosed $(>75 \%)$ coronary lesions. This study's cohort consisted of patients undergoing OPCAB; it accounted for more than $95 \%$ of patients undergoing isolated CABG and $77.7 \%$ of all patients who received BITA grafting during the same time period.

In addition to the beating heart technique, some investigators have recently reported that skeletonized harvesting of the ITA might contribute to reducing the number of wound infections, ${ }^{4,10,11,13}$ especially in patients with diabetes. ${ }^{12}$ However, those reports did not resolve the issue of whether skeletonized BITA is a risk factor for wound complications in OPCAB surgery. Higami and coworkers ${ }^{18,19}$ demonstrated that harvesting ITAs by ultrasonic skeletonization was safe and that the early angiographic patency rate was excellent. Encouraged by these results, we adopted this procedure; all of the ITAs in this study's cohort were harvested in a skeletonized fashion with an ultrasonic scalpel.

Wound infection occurred in $98(6.5 \%)$ of all patients: 79 had a surgical site infection in the broad sense, $7(0.47 \%)$ had a superficial infection, and $12(0.8 \%)$ had a deep infection (sternal osteomyelitis and/or mediastinitis). According to

TABLE 5. Multivariate analysis of risk factors for wound infection in diabetic patients

\begin{tabular}{lrrrr}
\hline \multicolumn{1}{c}{ Variables } & Wald $\boldsymbol{\chi}^{\mathbf{2}}$ & $\boldsymbol{P}$ value & HR & $\mathbf{9 5 \%} \mathbf{~ C I}$ \\
\hline Female gender & 19.782 & $<.0001$ & 3.5 & $2.0-6.0$ \\
ASO & 8.883 & .0029 & 2.8 & $1.4-5.4$ \\
CRF & 4.759 & .0291 & 2.3 & $1.1-4.8$ \\
BITA & 4.352 & .0368 & 2.5 & $1.1-6.1$
\end{tabular}

$H R$, Hazard ratio; $C l$, Confidence interval; $A S O$, atherosclerosis obliterans; $C R F$, chronic renal failure; $B I T A$, bilateral internal thoracic arteries. Overall $\chi^{2}=72.136$ with $4 d f, P<.0001$. 
previous reports, ${ }^{7,20-22}$ the wound infection rate after conventional $\mathrm{CABG}$ is $1.3 \%$ to $2.8 \%$, whereas the wound infection rate after OPCAB is $0.87 \% .^{5}$ In the present study, the rate of superficial and deep infections was $1.3 \%$ and the rate of deep sternal infections was $0.8 \%$. This is comparable with the lowest rate reported in previous studies.

On univariate analysis, preoperative risk factors such as female gender, ${ }^{3,9,13,22}$ congestive heart failure, ${ }^{23}$ chronic renal failure ${ }^{24}$ peripheral vascular disease, ${ }^{9,13,25}$ and diabetes ${ }^{10,13,22,26}$ have been previously identified. Paul and associates ${ }^{27}$ demonstrated that there was a good relationship between the EuroSCORE (both additive and logistic) and the postoperative sternal wound infection rate; our results confirm this finding.

Among the perioperative variables, use of BITA grafts, operation time, and blood transfusion were significant risk factors for wound infection (shown in Table 2). The Parisian study group ${ }^{6}$ and other investigators ${ }^{7}$ reported that BITA was one of the risk factors for deep sternal wound infection. Thus, many surgeons have hesitated to adopt this technique, especially for diabetic patients. In addition to BITA grafts, we also investigated the effect of gastroepiploic artery grafts. There was no difference in the wound infection rate between patients who received BITA and those who received BITA plus gastroepiploic artery. In agreement with our univariate analysis, Bellchambers and colleagues, ${ }^{22}$ in their prospective study, demonstrated that operation time, as well as female gender, obesity, and diabetes, was an independent risk factor. With respect to blood transfusions, not only the need to give a blood transfusion ${ }^{9,26}$ but also the number of units transfused ${ }^{28}$ have been correlated with an increased risk of bacterial infections. In the present study, patients with wound infections were almost twice as likely to have received a blood transfusion. Inasmuch as only $9(0.6 \%)$ patients had excessive postoperative bleeding and required resternotomy, resternotomy for bleeding was not found to be a risk factor, although some reports have shown that resternotomy for bleeding is a risk factor for wound infection. ${ }^{7,13}$

Logistic regression was done to identify the independent risk factors for wound infection. Table 3 shows that female gender (HR, 2.2; 95\% CI, 1.4-3.4), history of congestive heart failure (HR, 1.9; 95\% CI, 1.2-3.2), chronic renal failure (HR, 3.0; 95\% CI, 1.7-5.3), and diabetes (HR, 1.8; 95\% CI, 1.2-2.8) were independent risk factors. These variables have been previously found to be risk factors for wound infection after conventional CABG. ${ }^{9,10,13,22-24,26}$ Thus, the risk factors for wound infection in patients undergoing OPCAB are similar to those in patients undergoing $\mathrm{CABG}$ with extracorporeal circulation.

The subgroup of patients with diabetes was also analyzed; almost half (46.2\%) of the patients were diabetic, and diabetes was one of the 4 independent risk factors for wound infection on multivariate analysis. Furthermore, several investigators have reported that skeletonization of the ITA lowers the risk of sternal infection. ${ }^{4,10-13}$

On multivariate analysis (Table 5), the independent risk factors for wound infection after OPCAB were as follows: use of BITA harvested in a skeletonized fashion, female gender, atherosclerosis obliterans, and chronic renal failure. This analysis shows that, among diabetic patients, those who received BITA grafts, even those that were harvested in a skeletonized fashion with an ultrasonic scalpel, had a 2.5 -fold higher incidence of wound-related morbidity than those who did not receive BITA. Nevertheless, diabetic patients are most likely to benefit from BITA grafting because they have diffuse atherosclerotic coronary lesions. Endo, Tomizawa, and Nishida ${ }^{8}$ showed that diabetic patients had a higher long-term survival and lower rates of repeated CABG and myocardial infarction when BITA rather than SITA grafts was used.

In the present cohort of patients, the off-pump beating heart procedure and the ultrasonic skeletonization technique for BITA procurement were used. However, even with these techniques, wound infection was not eliminated, particularly in diabetic patients. Tight preoperative glucose control and continuous insulin infusion, ${ }^{29}$ rather than subcutaneous insulin infusion postoperatively, are the keys for reducing sternal infection in diabetic patients. Moreover, continuous insulin infusion reduces mortality in diabetic patients after $\mathrm{CABG}^{30} \mathrm{In}$ our institution, intraoperative precautions, such as double gloving, ${ }^{31}$ avoidance of bone wax,${ }^{32}$ and pinpoint hemostasis of the presternal space ${ }^{25}$ are not used. In addition, hair was removed by clippers on the day before operation in the present study. However, some reports have suggested that hair removal should be done just before the operation ${ }^{33}$ or that hair removal itself is associated with deep sternal wound infection. $^{6}$

There is no single approach that can be adopted to eliminate wound infections, although a combination of precautionary maneuvers may reduce the incidence. Given the present study's findings, our institution will continue with its current policy, inasmuch as diabetic patients are most likely to benefit from BITA. To reduce wound problems, we have adopted double gloving, avoidance of bone wax, pinpoint hemostasis of the presternal space, and postoperative continuous insulin infusion. The timing of and the necessity for hair removal are under review. Patient outcomes will need to be assessed after the adoption of such procedures.

This study had some limitations. First, this was a retrospective, observational study. Second, obesity was not assessed as a potential risk factor in patients undergoing $\mathrm{OPCAB}$; perioperative data were prospectively gathered from our institutional database based on EuroSCORE, which does not include the body mass index. ${ }^{16}$ Indeed, most previous reports ${ }^{6,7,9,10,20-22,25,26,29}$ found that obesity was correlated to the wound infection rate. However, some investigators, such as Orhan and colleagues, ${ }^{34}$ reported that obese patients 
did not have a higher incidence of wound infection than nonobese patients. Thus, the role of obesity as a risk factor remains controversial. The risk factors identified on our multivariate analyses are similar to those reported by other studies that considered obesity and are congruent with our clinical impression.

\section{References}

1. Cleveland JC Jr, Shroyer AL, Chen AY, Peterson E, Grover FL. Offpump coronary artery bypass grafting decreases risk-adjusted mortality and morbidity. Ann Thorac Surg. 2001;72:1282-8.

2. Sabik JF, Gilinov AM, Blackstone EH, Vacha C, Houghtaling PL, Navia J, et al. Does off-pump coronary surgery reduce morbidity and mortality? J Thorac Cardiovasc Surg. 2002;124:698-707.

3. Athanasiou T, Al-Ruzzeh A, Del Stanbridge R, Casula RP, Glenville BE, Amrani M. Is the female gender an independent predictor of adverse outcome after off-pump coronary artery bypass grafting? Ann Thorac Surg. 2003;75:1153-60.

4. Cartier R, Leacche M, Couture P. Changing pattern in beating heart operations: use of skeletonized internal thoracic artery. Ann Thorac Surg. 2002;74:1548-52.

5. Falagas ME, Rosmarakis ES, Rellos K, Michalopoulos A, Samonis G, Prapas SN. Microbiologically documented nosocomial infections after coronary artery bypass surgery without cardiopulmonary bypass. J Thorac Cardiovasc Surg. 2006;132:481-90.

6. The Parisian Mediastinitis Study Group. Risk factors for deep sternal wound infection after sternotomy: a prospective, multicenter study. J Thorac Cardiovasc Surg. 1996;111:1200-7.

7. Lu JC, Grayson AD, Jha P, Srinivasan AK, Fabri BM. Risk factors for sternal wound infection and mid-term survival following coronary artery bypass surgery. Eur J Cardiothorac Surg. 2003;23:943-9.

8. Endo M, Tomizawa $\mathrm{Y}$, Nishida $\mathrm{H}$. Bilateral versus unilateral internal mammary revascularization in patients with diabetes. Circulation. 2003;108:1343-9.

9. Savage EB, Grab JD, O'Brien SM, Ali A, Okum EJ, Perez-Tamayo RA, et al. Use of both internal thoracic arteries in diabetics increases deep sternal wound infection. Ann Thorac Surg. 2007;83:1002-7.

10. Matsa M, Paz Y, Gurevitch J, Shapira I, Kramer A, Pevny D, et al. Bilateral skeletonized internal thoracic artery grafts in patients with diabetes. J Thorac Cardiovasc Surg. 2001;121:668-74.

11. Kramer A, Mastsa M, Paz Y, Locker C, Pevni D, Gurevitch J, et al. Bilateral skeletonized internal thoracic artery grafting in 303 patients seventy years and older. J Thorac Cardiovasc Surg. 2000;120:290-7.

12. Peterson MD, Borger MA, Rao V, Peniston CM, Feindel CM. Skeletonization of bilateral internal thoracic artery grafts lowers the risk of sternal infection in patients with diabetes. J Thorac Cardiovasc Surg. 2003; 126:1314-9.

13. De Paulis R, de Notaris S, Scaffa R, Nardella S, Zeitani J, Del Giudice C, et al. The effect of bilateral internal thoracic artery harvesting on superficial and deep sternal infection: the role of skeletonization. $J$ Thorac Cardiovasc Surg. 2005;129:536-43.

14. Medalion B, Katz MG, Lorberboym M, Bder O, Schachner A, Cohen AJ. Decreased sternal vascularity after internal thoracic artery harvesting resolves with time: an assessment with single photon emission computed tomography. J Thorac Cardiovasc Surg. 2002;123: 508-11.

15. Boodhwani M, Lam BK, Nathan HJ, Mesana TG, Ruel M, Zeng W, et al. Skeletonized internal thoracic artery harvest reduces pain and dysesthesia and improves sternal perfusion after coronary artery bypass surgery: a randomized, double-blinded, within-patient comparison. Circulation. 2006;114:766-73.
16. Nashef SAM, Roques F, Michel P, Gauducheau E, Lemeshow S, Salamon R. European system for cardiac operative risk evaluation (EuroSCORE). Eur J Cardiothorac Surg. 1999;16:9-13.

17. Garner JS, Jarvis WR, Emori TG, Horan TC, Hughes JM. CDC definitions for nosocomial infections, 1988. Am J Infect Control. 1988;16: $128-40$.

18. Higami T, Kozawa S, Asada T, Shida T, Ogawa K. Skeletonization and harvest of the internal thoracic artery with an ultrasonic scalpel. Ann Thorac Surg. 2000;70:307-8.

19. Higami T, Yamashita T, Nohara H, Iwahashi K, Shida T, Ogawa K. Early results of coronary grafting using ultrasonically skeletonized internal thoracic arteries. Ann Thorac Surg. 2001;71:1224-8.

20. Birkmeyer NJ, Charlesworth DC, Hernandez F, Leavitt BJ, Marrin CA, Morton JR, et al. Northern New England Cardiovascular Disease Study Group. Obesity and risk of adverse outcomes associated with coronary artery bypass surgery. Circulation. 1998;97:1689-94.

21. Kuduvalli M, Grayson AD, Oo AY, Fabri BM, Rashid A. Risk of morbidity and in-hospital mortality in obese patients undergoing coronary artery bypass surgery. Eur J Cardiothorac Surg. 2002;22:787-93.

22. Bellchambers J, Harris JM, Cullinan P, Gaya H, Pepper JR. A prospective study of wound infection in coronary artery surgery. Eur J Cardiothorac Surg. 1999; 15:45-50.

23. Fowler VG Jr, O'Brien SM, Muhlbaier LH, Corey GR, Ferguson TB, Peterson ED. Clinical predictors of major infections after cardiac surgery. Circulation. 2005;112(9 Suppl):I358-65.

24. Cooper WA, O’Brien SM, Thourani VH, Guyton RA, Bridges CR, Szczech LA, et al. Impact of renal dysfunction on outcomes of coronary artery bypass surgery: results from the Society of Thoracic Surgeons National Adult Cardiac Database. Circulation. 2006;113:1063-70.

25. Ura M, Sakata R, Nakayama Y, Arai Y. Bilateral pedicled internal thoracic artery grafting. Eur J Cardiothorac Surg. 2002;21:1015-9.

26. Olsen MA, Lock-Buckley P, Hopkins D, Polish LB, Sundt TM, Fraser VJ. The risk factors for deep and superficial chest surgical-site infections after coronary artery bypass graft surgery are different. J Thorac Cardiovasc Surg. 2002;124:136-45.

27. Paul M, Raz A, Leibovici L, Madar H, Holinger R, Rubinovitch B. Sternal wound infection after coronary artery bypass graft surgery: validation of existing risk scores. J Thorac Cardiovasc Surg. 2007;133: 397-403.

28. Chelemer SB, Prato BS, Cox PM Jr, O'Connor GT, Morton JR. Association of bacterial infection and red blood cell transfusion after coronary artery bypass surgery. Ann Thorac Surg. 2002;73:138-42.

29. Lazar HL, Chipkin SR, Fitzgerald CA, Bao Y, Cabral H, Apstein CS. Tight glycemic control in diabetic coronary artery bypass graft patients improves perioperative outcomes and decreases recurrent ischemic events. Circulation. 2004;109:1497-502.

30. Furnary AP, Gao G, Grunkemeier GL, Wu Y, Zerr KJ, Bookin SO, et al. Continuous insulin infusion reduces mortality in patients with diabetes undergoing coronary artery bypass grafting. $J$ Thorac Cardiovasc Surg. 2003;125:1007-21.

31. Wong PS, Young VK, Youhana A, Wright JE. Surgical glove punctures during cardiac operations. Ann Thorac Surg. 1993;56:108-10.

32. Nelson DR, Buxton TB, Luu QN, Rissing JP. The promotional effect of bone wax on experimental Staphylococcus aureus osteomyelitis. J Thorac Cardiovasc Surg. 1990;99:977-80.

33. Alexander JW, Fischer JE, Boyajian M, Palmquist J, Morris MJ. The influence of hair-removal methods on wound infections. Arch Surg. 1983;118:347-52.

34. Orhan G, Bicer Y, Aka SA, Sargin M, Simsek S, Senay S, et al. Coronary artery bypass graft operations can be performed safely in obese patients. Eur J Cardiothorac Surg. 2004;25:212-7. 